\title{
Group Classes and Measurements: Towards Made to Measure
}

\author{
Jean-Marc SURVILLE \\ Lectra, France
}

\begin{abstract}
A group of 1700 men was studied for clothing purposes. Classification based on the HOAXY was applied to this population and only the HXY silhouettes were considered for the study. The $\mathrm{H}$ silhouette was the most representative with 1184 individuals belonging to this group. Using depth measurements based on the bust and waist, we proposed 3 side view groups "I" " P" and " D": "I" is equal for both bust and waist depths, $\mathrm{P}$ is bust prominent compared to the waist, and $\mathrm{D}$ is belly prominent. This classification will be linked to garment construction. The principle is to obtain a size chart based on classical bust distribution. All the measurements involved in the construction and alteration of the garment are taken into account and a regression calculation is carried out for each measurement.

Measurement "5030" is the length from the neck to across back for the detection of stooping. Regression gives the intervals to be used for standard grading. The points in away from the cloud give the proportion of individuals for whom alterations would be necessary (here stoop posture). The process was enhanced to calculate the distance of individuals for any measurement compared to the regression, in order to calculate the value of the alterations to be applied to the garment geometry. In conclusion, we demonstrate that any classification may be key in an industrial process. In addition, the population clustering is more industry dependant than any anthropological purpose.
\end{abstract}

Keywords: Anthropometry, Scanner, Body shape, HOAX statistics, postures

\section{Introduction}

The purpose of this study is to evaluate a grading system based on direct anthropometric data issued from a body scanner. Our previous studies show silhouette distribution as HXY shapes for men. Analysis of a group of 1700 men makes it possible to elaborate another way of sizing.

\section{Method}

We based our study on simple Cartesian coordinates to represent the link between 2 measurements. The classical statistics referring to Principle component analysis have already been carried out on this population (27).

Instead of classification calculated via histogram groups, we considered the total population to use an analysis of linear regression.

\subsection{Technology (see ref 20)}

$3 \mathrm{D}$ volumes were scanned. A total of 180 measurements per scan were organized in an Oracle database.

We used the SPAD software as the data mining tool (22).

\subsection{Results using width ratios for bust waist and hip}

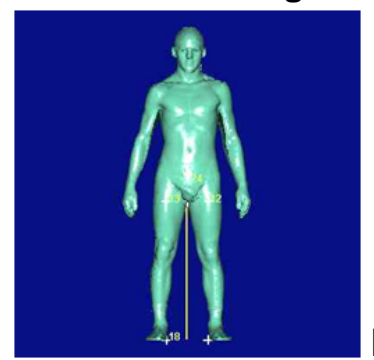

H 1184

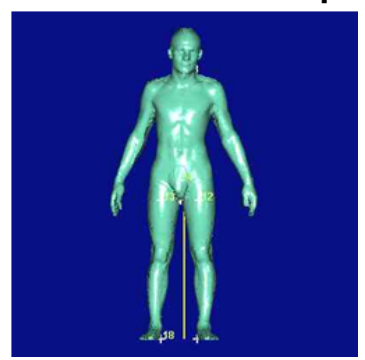

$\times 46$

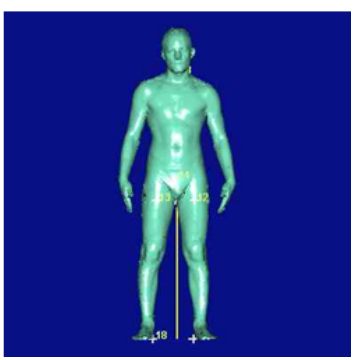

The $\mathrm{H}$ silhouette was the most representative with 1184 individuals belonging to this group. 
Using depth measurements based on the bust and waist, we proposed 3 side view groups "l" ," P" and " D": "I" is equal for both bust and waist depths. $\mathrm{P}$ is bust prominent compared to the waist, and $\mathrm{D}$ is belly prominent.
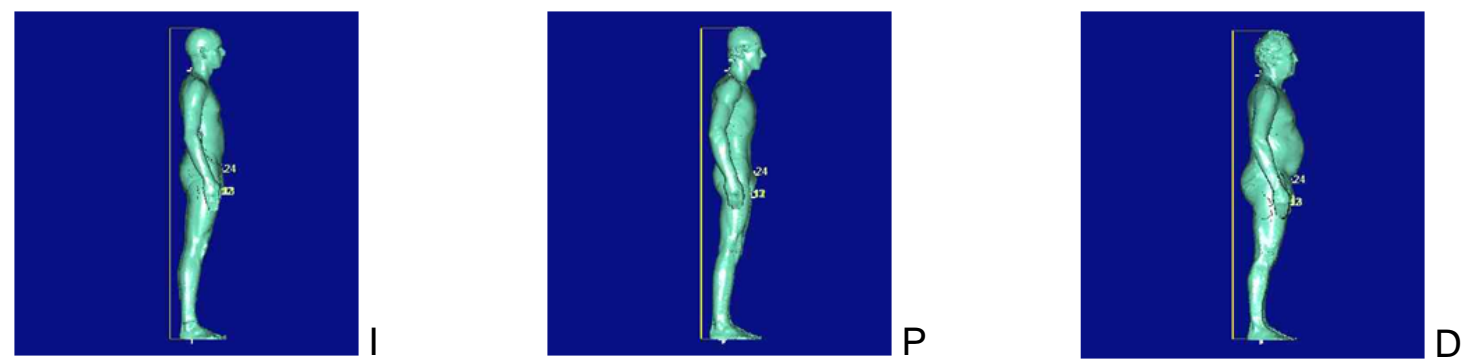

We obtained HI, HP, HD, XI, XP, YI, YP classes.

Such classification gives too many classes to be managed for garment grading.

\section{Linear regression on total population}

We first compared bust and waist used in classical classification for sizing (drop as a signed difference between bust and waist).

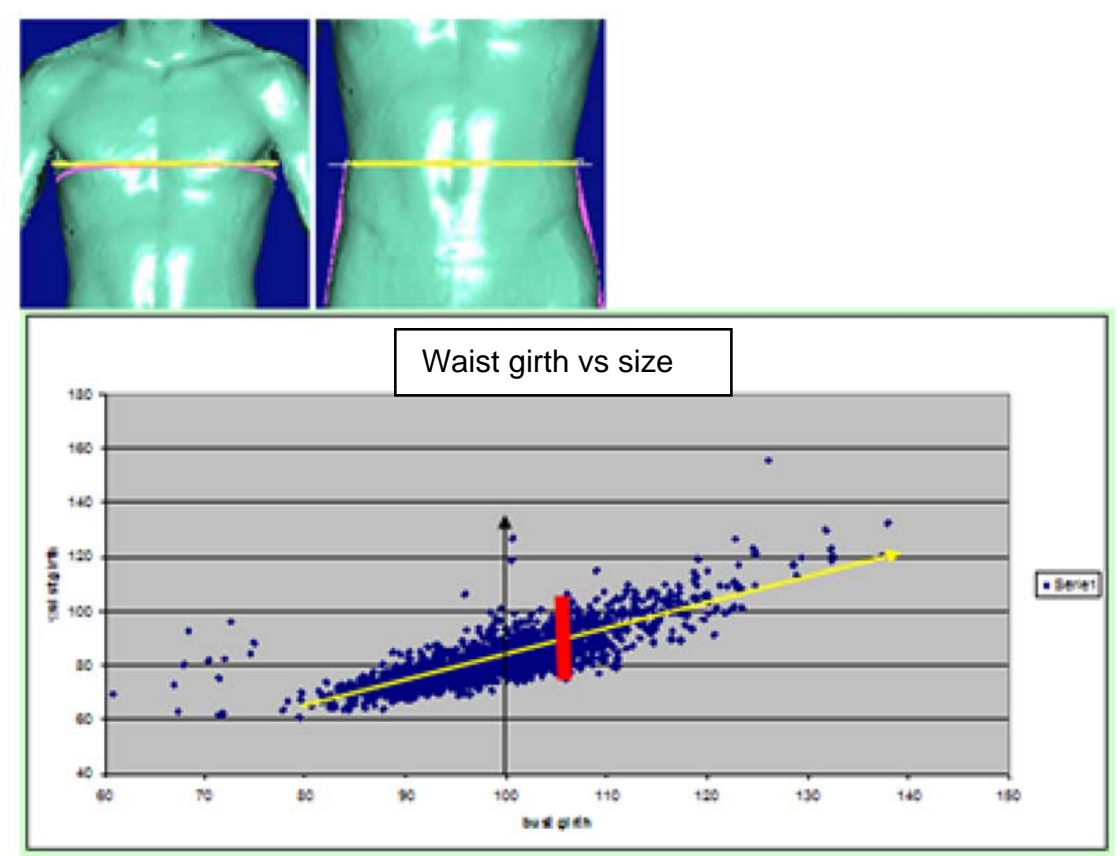

B 76 $=60 \mathrm{~cm}$ B $120=106 \mathrm{~cm}$ interval $=4 \mathrm{~cm}$ For size 50 (bust $100 \mathrm{~cm}$ ) average is 84 (drop 8 )

Min $=72 \mathrm{~cm} \max =92 \mathrm{~cm}$

The regular measurements are given using the yellow arrow.

The total depth of the cloud gives an idea of the alteration for example $+j-10 \mathrm{~cm}$ for size 50 (red line)

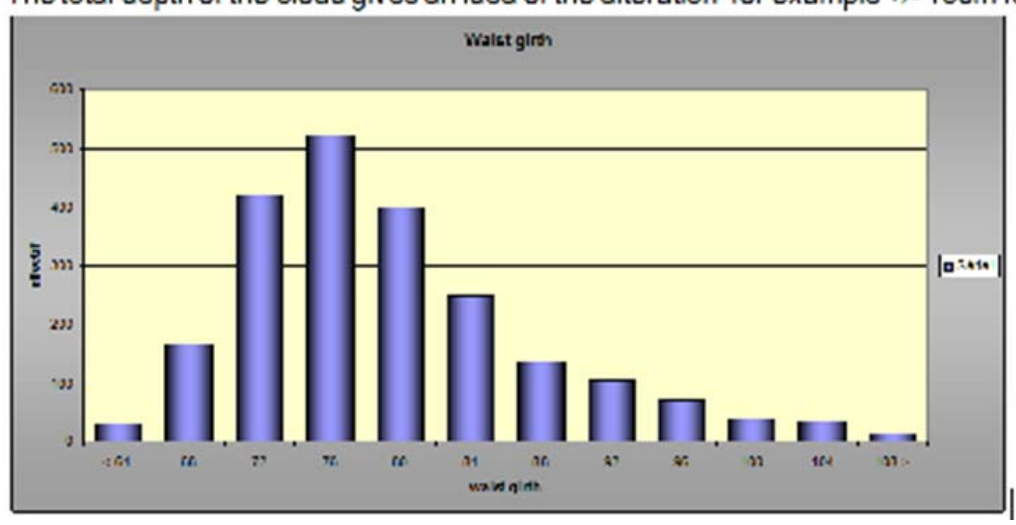


Relation for the hip
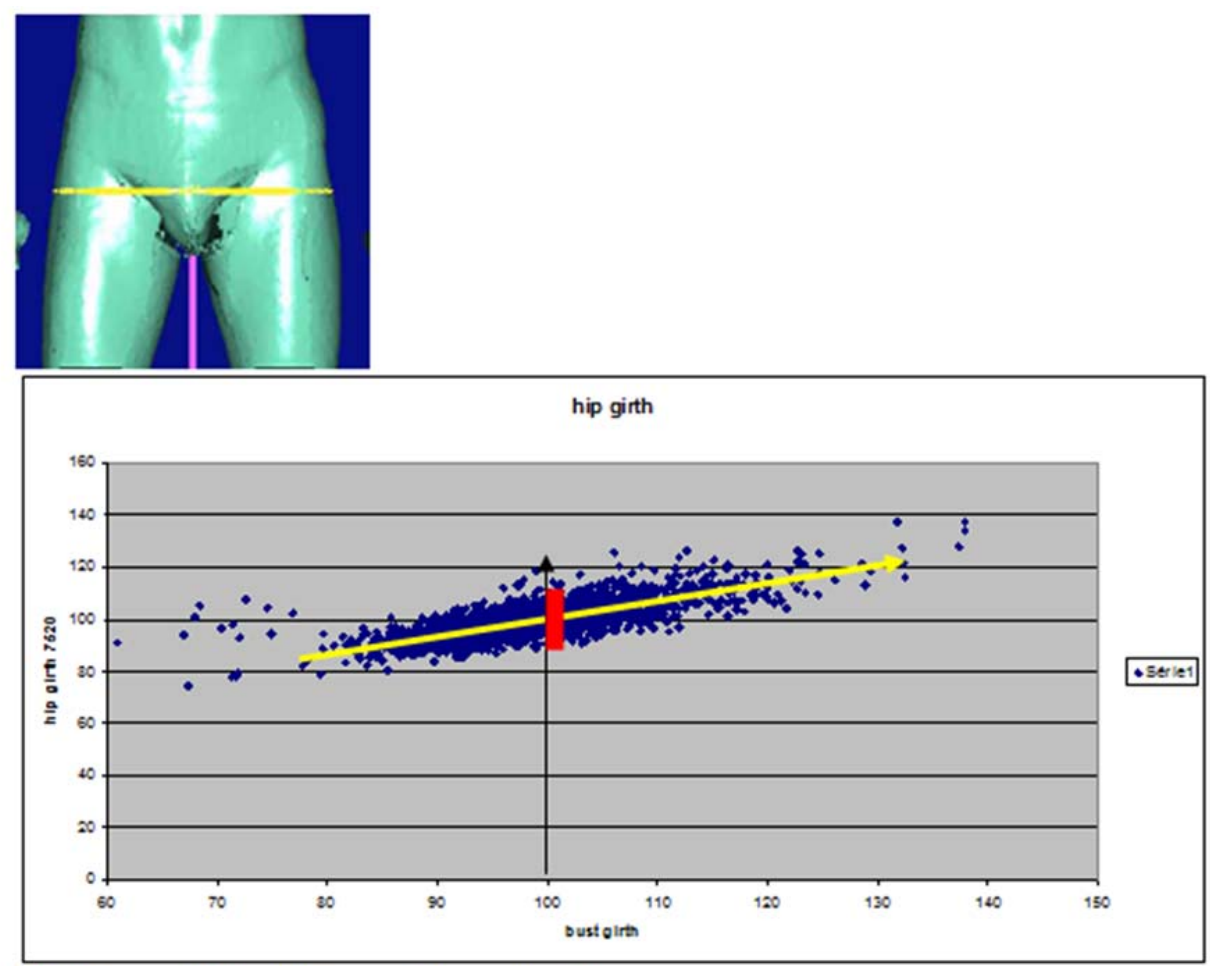

$80: 85 \mathrm{~cm} \quad 120: 115 \mathrm{~cm} \quad$ Interval $=3 \mathrm{~cm}$

For size 50 , alteration is $+/-10 \mathrm{~cm}$

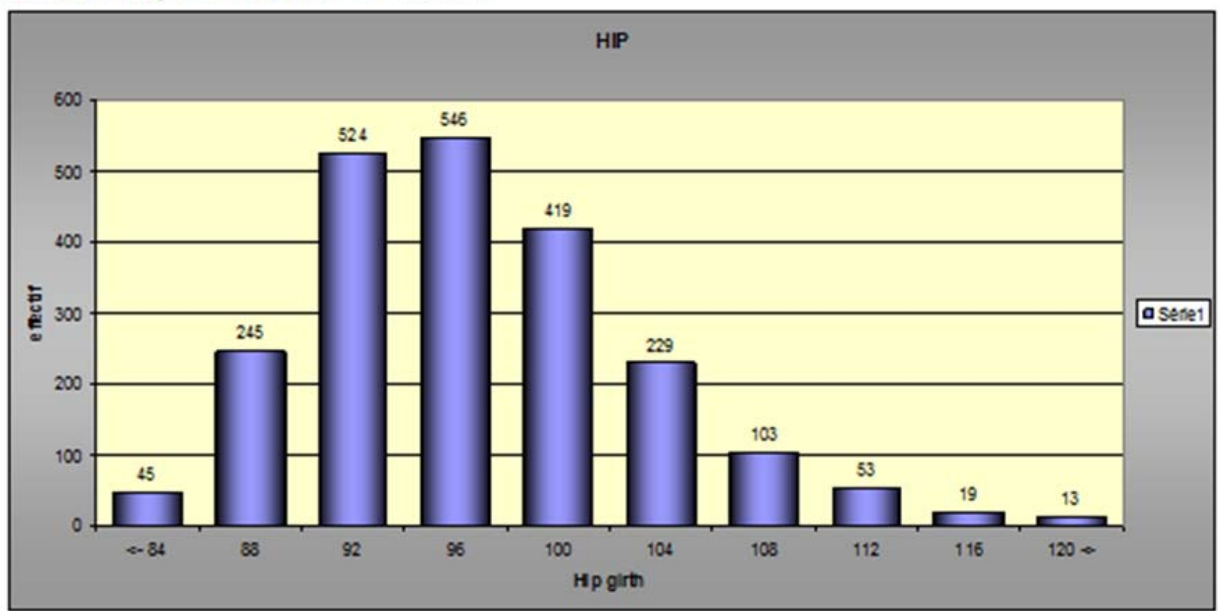

These charts show some points that do not correspond to the rest of the population. They are generally eliminated from statistics except when real people are to be dressed. 
Back length

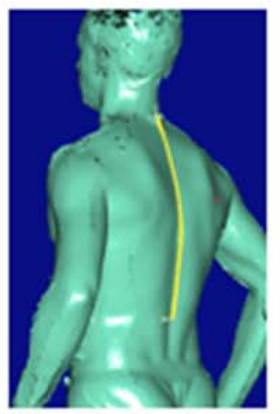

Values are given by the body chart.

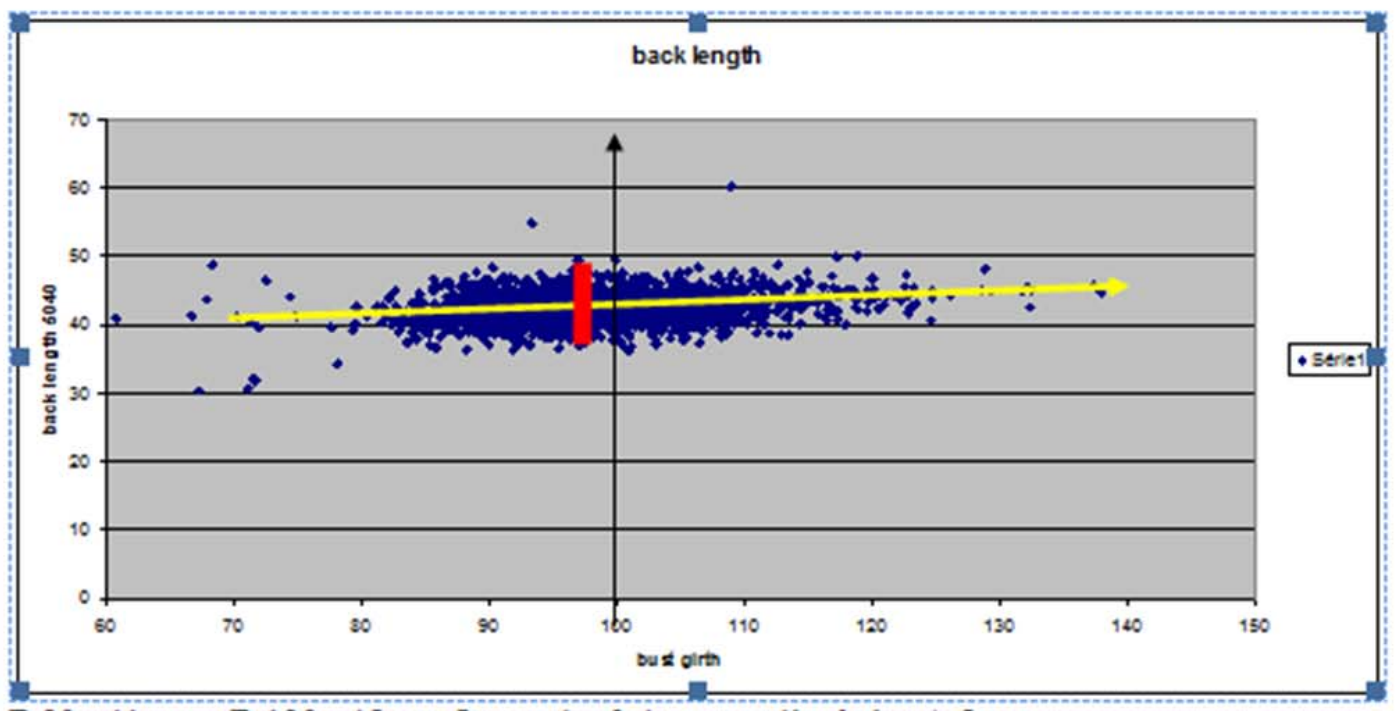

B $80: 41 \mathrm{~cm}$ B $120: 45 \mathrm{~cm}$ Interval $=0.4 \mathrm{~cm}$ amplitude is $+/-5 \mathrm{~cm}$

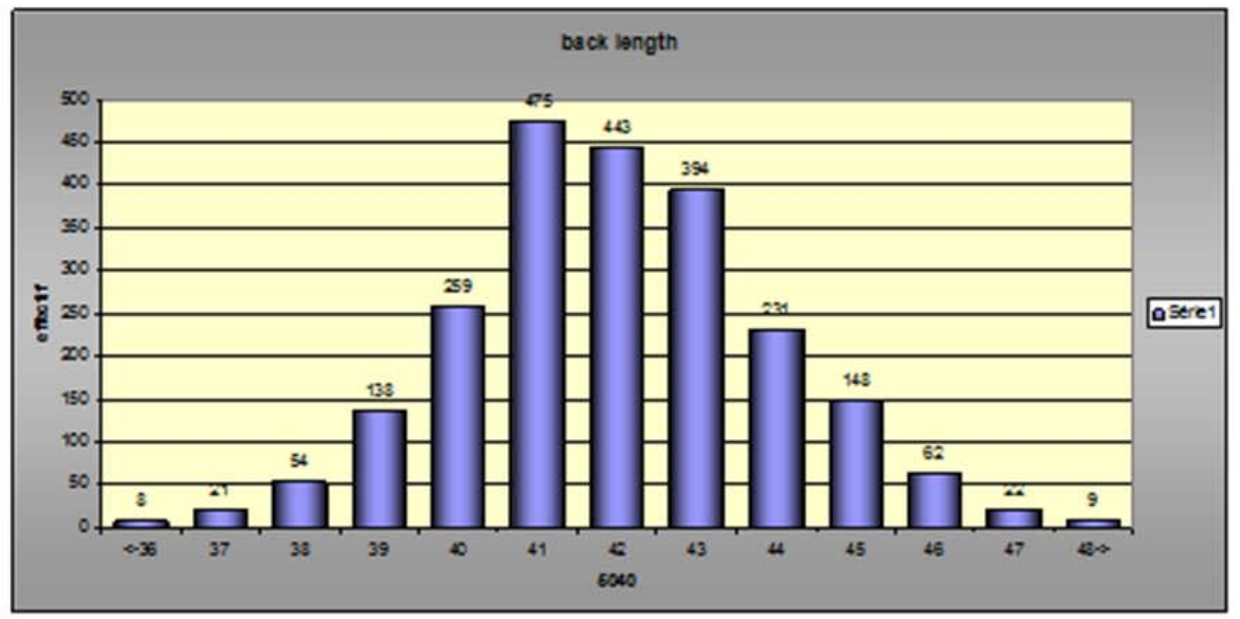

The back length is little dependent on bust girth. This is an obvious observation that is useful to justify the grading for jacket length. 


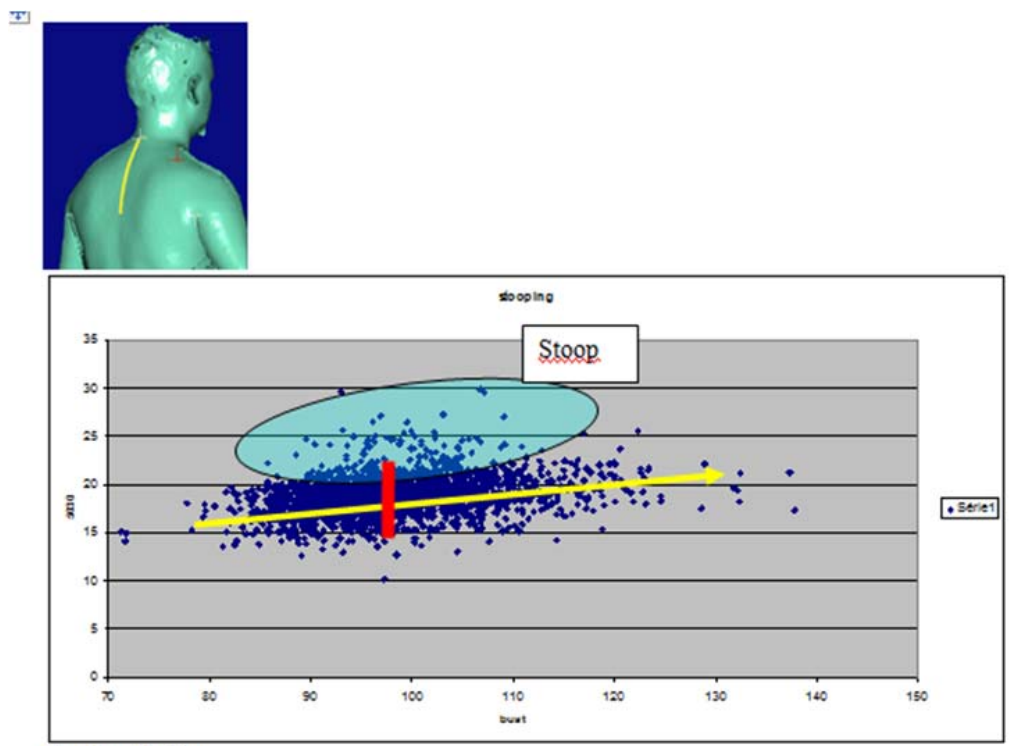

\section{Stooping detection}

We use Human solution 5030 (see picture). Every point is the couple for a soldier, "5030", Bust Bust $80 \mathrm{~cm}$ : back $16 \mathrm{~cm}$ bust $120 \mathrm{~cm}$ : back $20 \mathrm{~cm}$ interval $=0.4 \mathrm{~cm}$ Amplitude is $+/-4 \mathrm{~cm}$

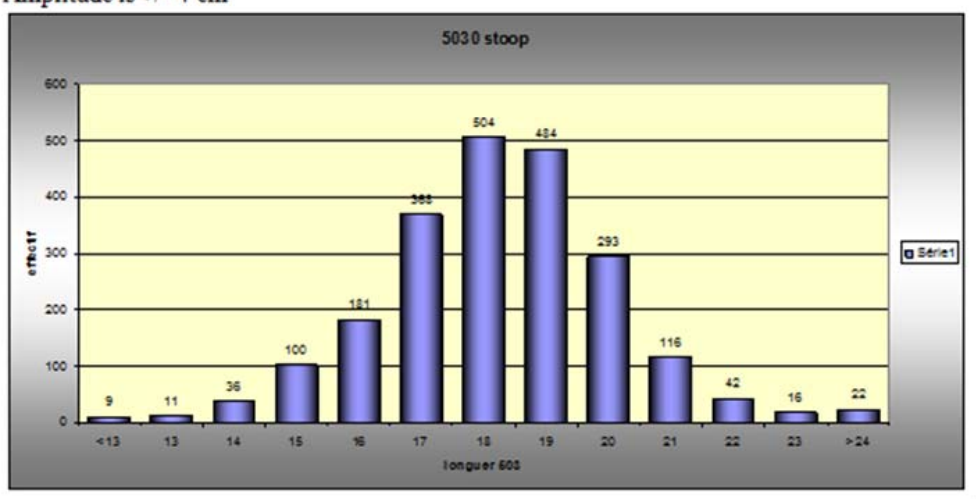

The top back length is generally considered as stoop measurement in menswear.

Here we have the graphic representation of the stoop population.
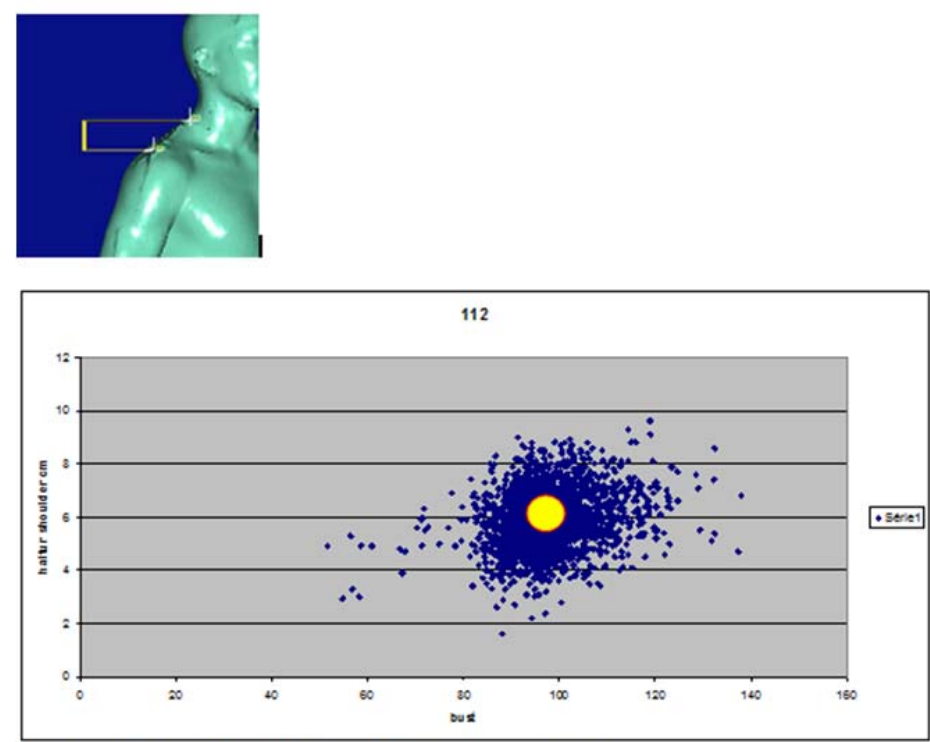

Central value $=6 \mathrm{~cm}$ is independent from bust girth. (see garment value $=6 \mathrm{~cm}$ )

Any value may be considered to the $6 \mathrm{~cm}$ reference.

The shoulder height is independent of bust girth. 


\section{Pant evaluation}

The reference measurement is the waistband.

Here we consider only 2 characteristic measurements.

The tight girth

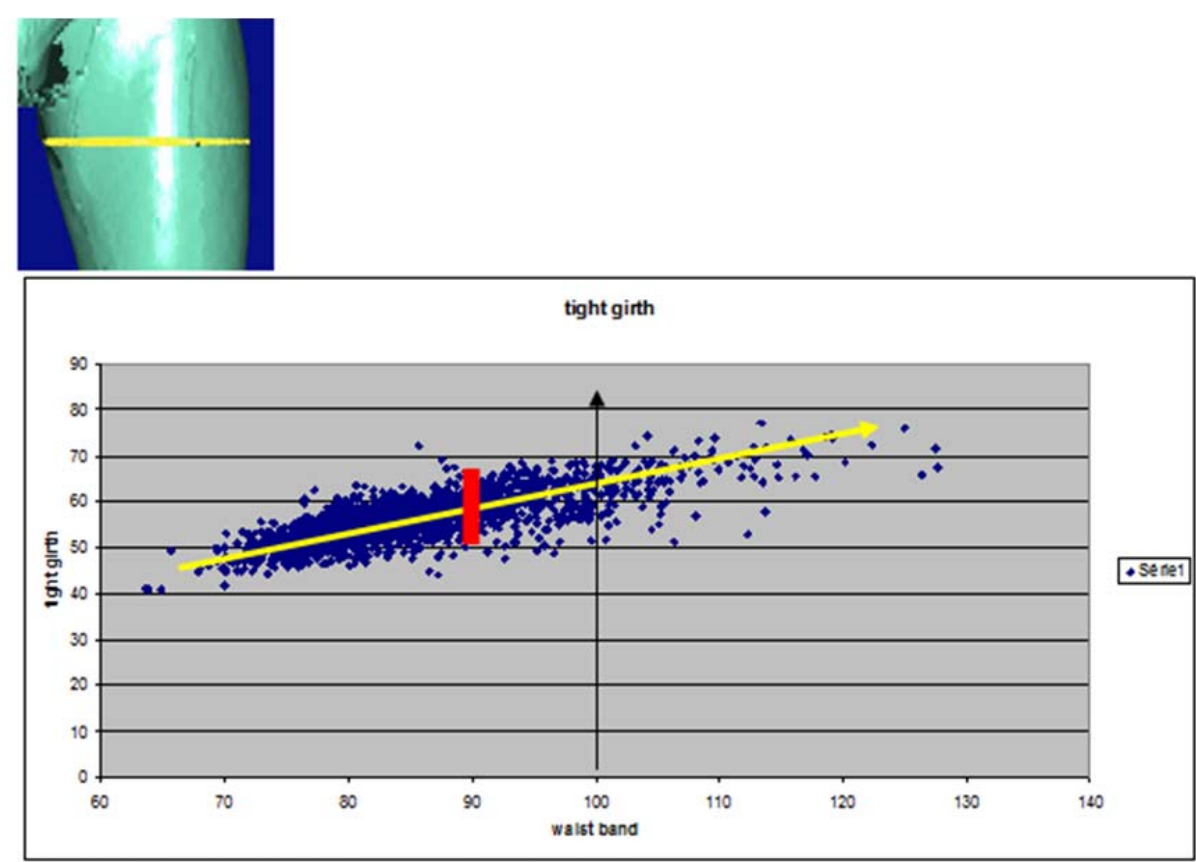

W $70: 46 \mathrm{~cm} \mathrm{~W} 100: 64 \mathrm{~cm}$ interval $=2.4 \mathrm{~cm}$

Amplitude is $+/-7 \mathrm{~cm}$

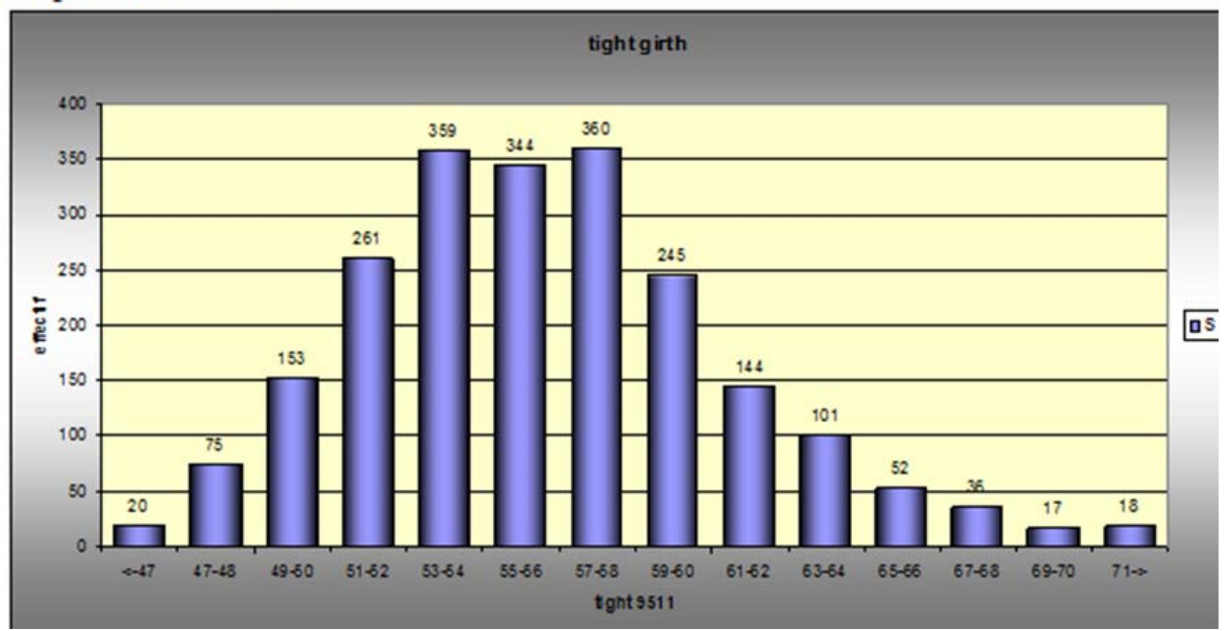


The waist to hip length

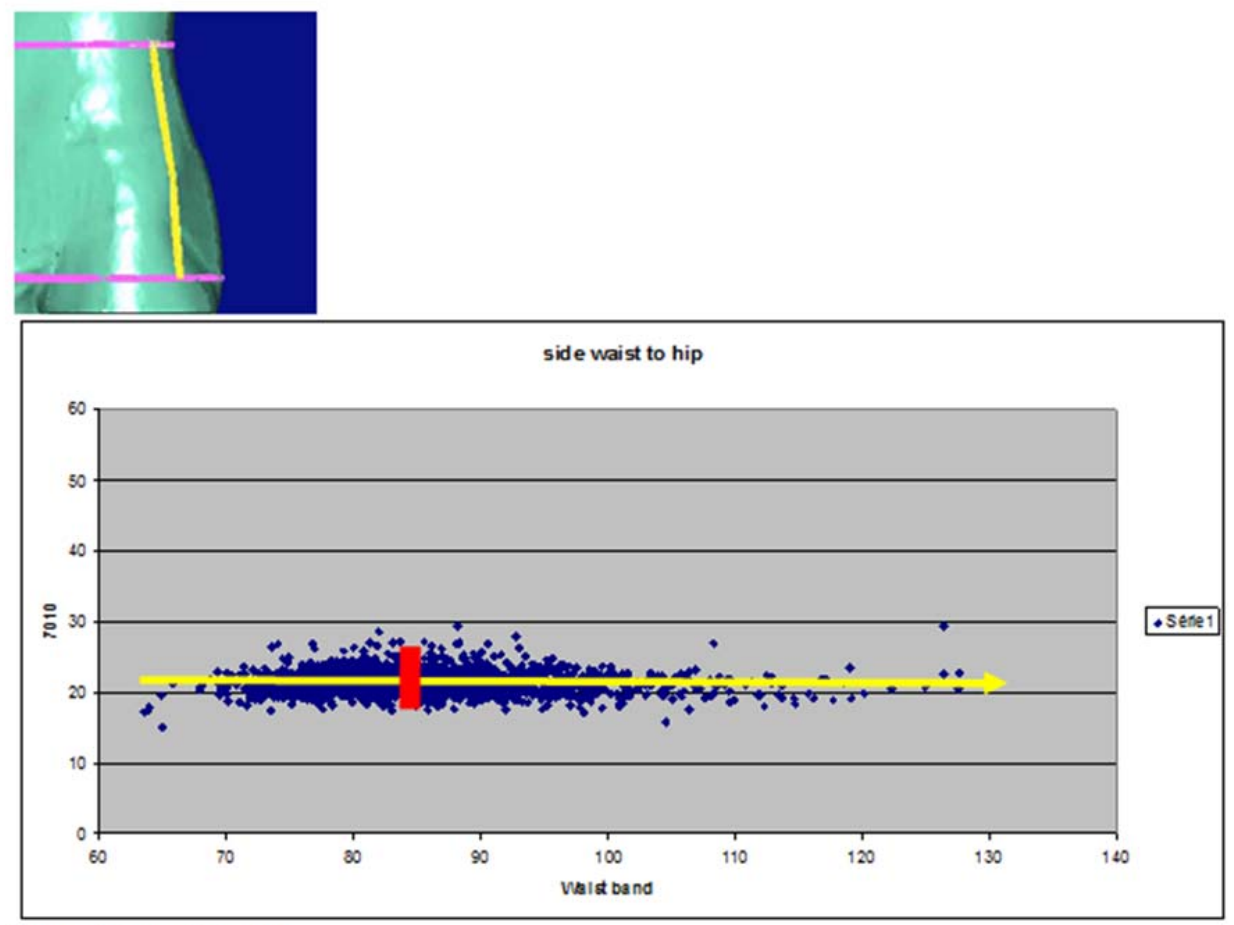

The side wait to hip

Average value $21.3 \mathrm{~cm}$ for all sizes with an amplitude of $+/-3 \mathrm{~cm}$

This information is useful to justify a regular standard height of the pant rise.

The waist to hip measurement is totally independent and may be considered as constant for garment construction.

\section{Discussion}

This graphic approach using linear regression is a practical tool for grading evaluation based on the analysis of a real population and non-related to common garment values.

The process has been tested to level out grading intervals (24) and is of great interest for subjects whose measurements are not situated within the regular cloud as shown in the graphs. Most of the time the extra value for a measurement may be applied as a made to measure alteration in garment production.

\section{Conclusions}

This method is another way to elaborate grading rules. The central values for the basic and intervals calculated on the linear regression is a concrete process to establish a size chart.

Those people whose measurements are not situated within the regular cloud as shown in the graphs may be identified and as a percentage provide useful information for the decision of made to measure treatment as a matter of industrial process.

\section{References}

(1) Rand W.H. "Objective criteria for the evaluation of clustering methods", in Journal of American Statistical Association, Vol 66 (1971)

(2) Salusso-Deonier CJ, Markee NL, Pedersen EL., Developing realistic stimuli for assessing observers' perceptions of male and female body types. Percept Mot Skills. 1991 Apr;72(2):60310.

(3) Z. Takamura Fashion With Style: Ladies Fashion Items Graphic Sha Pub Co (March 1993) 176 p 
(4) R. Weiss Chase CAD for Fashion Design Prentice Hall; Pap/Dis edition (January 3, 1997) 174 pages

(5) DUFFY (Mary).The H.O.A.X fashion formula. Tucson, Arizona, The body press, 1987, 246p

(6) Carter, J.E.L., \& Heath, B.H. (1990). Somatotyping - Development and Applications. Cambridge: Cambridge University Press..

(7) Elizabeth L. Liechty, Della N. Pottberg-Steineckert, Judith A. Rasband Fitting \& Pattern Alteration: A Multi-Method Approach Fairchild Pubns; Student edition (June 10, 1992)

(8) Priya Devarajan, Dr. Cynthia L. Istook, Validation of female figure identification technique (FFIT) for apparel software Journal of Textile and Apparel, Technology and Management 4,(1) http://www.tx.ncsu.edu/jtatm/volume4issue1/articles/lstook/devarajan full 106 04.pdf

(9) Liu Chi, Richard Kennon, (2006) "Body scanning of dynamic posture", International Journal of Clothing Science and Technology, Vol. 18 Iss: 3, pp.166 - 178

(10) D. Gupta, B.R. Gangadhar, (2004) "A statistical model for developing body size charts for garments", International Journal of Clothing Science and Technology, Vol. 16 Iss: 5, pp.458 469

(11) Young Sook Cho, Takuya Komatsu, Masayuki Takatera, Shigeru Inui, Yoshio Shimizu, Hyejun Park, (2006) "Posture and depth adjustable 3D body model for individual pattern making", International Journal of Clothing Science and Technology, Vol. 18 Iss: 2, pp.96-107

(12) Solinger, J., Apparel Manufacturing Handbook. Analysis Principles, and Practice, Bobbin Media Corp., Columbia, SC, 1988

(13) L J Connell, P Ulrich , A Knox, G Hutton, D Woronka, S Ashdown Body Scan Analysis for Fit Models Based on Body Shape and Posture Analysis NTC Project: S01-AC27 (formerly 101-27)

(14) Simmons, K., Istook, C.L. and Devarajan, P. (2004a), "Female figure identification technique (FFIT) for apparel - part I: describing female shapes", Journal of Textile and Apparel Technology and Management, Vol. 4 No.1.

(15) Simmons, K., Istook, C.L. and Devarajan, P. (2004b), "Female figure identification technique (FFIT) for apparel - part II: development of shape sorting software", Journal of Textile and Apparel, Technology and Management, Vol. 4 No. 1.

(16) Jeong Yim Lee, Cynthia L. Istook, Yun Ja Nam, Sun Mi Park, (2007) "Comparison of body shape between USA and Korean women", International Journal of Clothing Science and Technology, Vol. 19 Iss: 5, pp.374 - 391

(17) Susan P. Ashdown and Hyunshin Na Comparison of 3-D Body Scan Data to Quantify UpperBody Postural Variation in Older and Younger Women Clothing and Textiles Research Journal October 2008 26: 292-307

(18) F.L. Zangrillo, Fashion Design for the Plus-Size, Fairchild Pubns (February 9, 1990) $192 \mathrm{p}$

(19) CHAVENT M. et al (2001), Critère de Rand asymétrique http://www.math.ubordeaux.fr/ chavent/sfc01.pdf

(20) A. Caillaud, Méthodes statistiques appliquées en anthropométrie, érude morphologique sur un échantillon de femmes, 2006 Master MSRO Université Bordeaux 1.

(21) S. HERICHI, Méthodes statistiques appliquées en anthropométrie, Analyse du changement du corps entre la posture debout et la posture assise. 2009 Master MIMSE Université Victor Segalen Bordeaux 2.

(22) Lambert T., Lebart L., Morineau A., Pleuvret P. (1996) - Manuel de référence de SPAD. CISIACERESTA, Saint-Mandé.

(23) CHAVENT M. et al (2001), Critère de Rand asymétrique http://www.math.ubordeaux.fr/ chavent/sfc01.pdf

(24) Jean-Marc Surville: Garment grading system. Lectra Systemes May 1998: US 5757661

(25) Jean-Marc SURVILLEa, Sonia HERICHIb, HOAXY Body Shapes and Fashion Formula International Conference on 3D Body Scanning Technologies, Lugano, Switzerland, 19-20 October 2010 p 249

(26) AISSOUNI R. Méthodes statistiques appliqués en anthropométrie : élaboration des barèmes de tailles en habillement, (2004) Master MSRO Université Bordeaux 1. 